\title{
UNIVERSITYOF
}

FORWARD

THINKING

WESTMINSTER用

WestminsterResearch

http://www.westminster.ac.uk/westminsterresearch

Impact of 5G Waveforms on Energy Harvesting Rectifier

Performance

Olukoya, O., Mlačić, B. and Budimir, D.

This is a copy of the author's accepted version of a paper subsequently to be published in the proceedings of the IEEE MTT-S Wireless Power Transfer Conference (WPTC), part of Wireless Power Week (WPW2019), London, UK, 17 - 21 Jun 2019.

The final published version is available online at:

https://doi.org/10.1109/WPTC45513.2019.9055635

(C) 2019 IEEE . Personal use of this material is permitted. Permission from IEEE must be obtained for all other uses, in any current or future media, including reprinting/republishing this material for advertising or promotional purposes, creating new collective works, for resale or redistribution to servers or lists, or reuse of any copyrighted component of this work in other works.

The WestminsterResearch online digital archive at the University of Westminster aims to make the research output of the University available to a wider audience. Copyright and Moral Rights remain with the authors and/or copyright owners. 


\section{Impact of 5G Waveforms on Energy Harvesting Rectifier Performance}

\author{
Oludotun Olukoya \\ Wireless Communications \\ Research Group \\ University of Westminster \\ London, UK
}

\author{
Boris Malcic \\ Faculty of ElectricalEngineering \\ University of Banja Luka \\ Banja Luka, B\&H \\ boris.malcic@etf.unibl.org
}

\author{
Djuradj Budimir \\ Wireless Communications \\ Research Group \\ University of Westmonster \\ London, UK \\ d.budimir@wmin.ac.uk
}

\author{
Djuradj Budimir \\ School of Electrical \\ EngineeringUniversity of \\ Belgrade \\ Belgrade, Serbia \\ d.budimir@etf.rs
}

\begin{abstract}
In this paper, an evaluation of impact of $5 \mathrm{MHz} 5 \mathrm{G}$ FBMC waveforms on energy harvesting rectifier performance is presented. The 5 MHz 5G FBMC signals are used in Matlab. The simulated CCDFs of the rectifier for $5 \mathrm{MHz} 5 \mathrm{G}$ signals at different input powers at $1.5 \mathrm{GHz}$ are illustrated
\end{abstract}

Keywords-Rectifiers, FBMC, Peak-to-Average-Power Ratio (PAPR), Complementary Cumulative Distribution Function (CCDF).

\section{INTRODUCTION}

The emergence of microwave power transmission (MPT) plays a vital role in wirelessly powered circuits such as RF identification (RFID) and other low power wireless sensors [1]. The total efficiency of the microwave wireless system depends mainly on the RF-DC conversion efficiency of the rectifier circuits which has made high efficiency rectifier design very important.

Recent researches have focused on different topologies to improve RF-DC conversion efficiency performance. Some of such topologies and models have been proposed in [2] - [5]. It was found that the electromagnetic energy is generally not constant due to the varying input power and operating frequency which leads to input impedance variation. The impedance variation degrades the rectifier performance due to the nonlinearity of the rectifying device. Another drawback from some of these improvements was due to load variation at the output of the rectifier which also leads to input impedance modification that can cause efficiency to deteriorate. To overcome the drawbacks and boosts robustness against the input power and output load variations, some further techniques were developed. Some of those solutions included resistance compression networks [6] which helped to improve the input impedance variation issue but still had bandwidth efficiency issues.

Recent works have now focused on the performance of rectifiers under different signal types rather than just considering the matching network and device selection. Previous work had considered single and two tone modes of operation. It has been observed when investigating multi tone signals that high peak-to-average power ratio (PAPR) may lead to a higher RF-DC conversion efficiency than its equivalent signal with the same input power [7]. This work optimizes the RF-DC efficiency performance by identifying the optimal load resistance whilst achieving a high PAPR using digitally modulated signals.

\section{ENERGY HARVESTING RECTIFIERS}

The design of the rectifier circuit is essential to achieve the best RF-dc conversion efficiency, for this purpose a single stage, full-wave; peak to peak rectifier has been used [7]. A single stage rectifier with/without branch line coupler is designed. Full wave rectifiers can achieve higher RF to DC efficiency than the half-wave. In this design the zero-bias Schottky diodes (Skyworks SMS7630) have been selected as the rectifying components. The selection of the commercially available Schottky diodes has been made considering the lowest zero-bias capacitance $C_{j 0}$ and the highest saturation current $I_{s}$, since these are the two parameters directly responsible for the RF-DC conversion efficiency. Fig. 1 shows the schematic of the designed and optimised rectifier without BLC. The schematic of the designed and optimised rectifier with BLC is shown in Fig. 2. At the input of the rectifier a T-type matching network was used to assure the highest power transfer between input and output power through converting the $50 \Omega$ input impedance of the antenna to match the conjugate input impedance of the rectifier. Then, the BLC and the rectifier are combined. The results are obtained and analysed in the next section for RF CCDF of $5 \mathrm{MHz}$ FBMC waveforms and efficiency performance. 


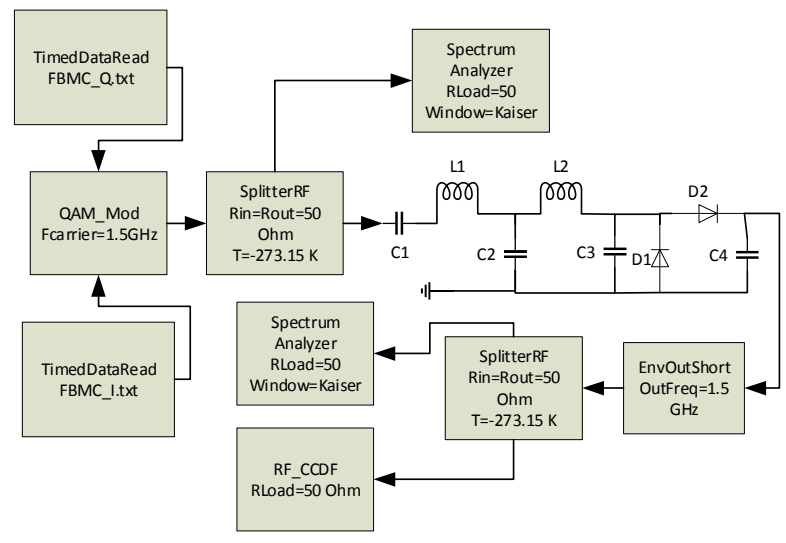

Fig. 1: Schematic of the rectifying circuit without BLC

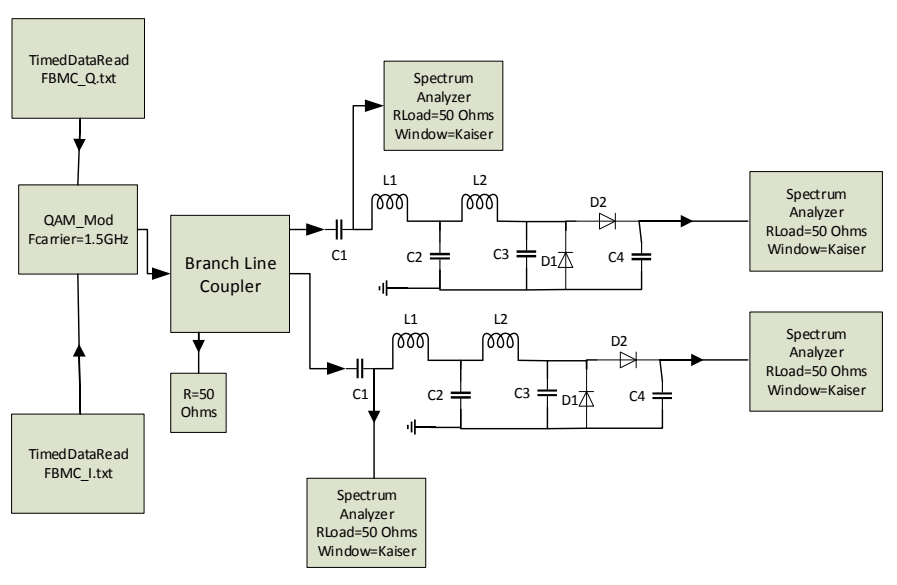

Fig. 2: Schematic of the rectifying circuit with BLC

\section{RESULTS}

To evaluate the nonlinear properties at the energy harvesting rectifier's output the $5 \mathrm{MHz}$ FBMC waveforms are used. FBMC transmits data by filtering each sub-carrier individually rather than the whole sub-band. FBMC signal can achieve better spectral efficiency as it does not use cyclic prefix and respects Nyquist rate. In contrast to CP-OFDM, the low side-lobes, steep slope at the edges of the signal band and the use of larger number of subcarriers during transmission all help to improve spectral efficiency at the output of the wireless transmitter [8].The 5G FBMC waveforms were generated using Matlab. Simulation results were obtained using the model of the signal generator in Keysight's Agilent ADS software. The CCDF argument (Signal Range in $\mathrm{dB}$ ) is represented as the ratio of a given power level ( $\mathrm{P}$ in $\mathrm{dBm})$ over the average power $\left(\mathrm{P}_{\mathrm{A}}\right.$ in $\mathrm{dBm})$. CCDF depicts the fraction of time it takes the instantaneous power of the signal to be equal or greater than the CCDF argument. The CCDF curve shows the probability that the instantaneous signal power will be higher than the average signal power by the certain amount of $\mathrm{dB}$.
The independent axis of the CCDF curve shows power level in $\mathrm{dB}$ with respect to the signal average power level $(0 \mathrm{~dB}$ corresponds to the signal average power level).

The CCDF of 5G FBMC signals and their corresponding PAPR value for the designed rectifier is described below. Waveform comparison and CCDF results are evaluated at the same bandwidth and different input power levels. Simulated CCDF and PAPR $\left(\mathrm{P} / \mathrm{P}_{\mathrm{A}}\right.$ in $\left.\mathrm{dB}\right)$ of the energy harvesting rectifier without coupler with $5 \mathrm{MHz} 5 \mathrm{G}$ FBMC signals at input power levels of $-10 \mathrm{dBm}, 0 \mathrm{dBm}$ and $10 \mathrm{dBm}$ are presented in Fig. 3. Fig. 5, and Fig. 7 respectively. In the Fig. 5, we can see that the instantaneous signal power exceeds the average signal power $(0$ $\mathrm{dB}$ ) for about $30 \%$ of the time. Also, we can see that the instantaneous signal power exceeds the average signal power by $-10 \mathrm{~dB}$ only about $72 \%$ of the time.

The simulated CCFD of various output power spectra densities of the rectifier with coupler with $5 \mathrm{MHz}$ FBMC at input power of $-10 \mathrm{dBm}, 0 \mathrm{dBm}$ and $10 \mathrm{dBm}$ are shown in Fig. 4, Fig. 6 and Fig. 8 respectively. In the Fig. 6, we can see that the instantaneous signal power exceeds the average signal power $(0 \mathrm{~dB})$ for about $30 \%$ of the time. Also, we can see that the instantaneous signal power exceeds the average signal power by $-10 \mathrm{~dB}$ only about $70 \%$ of the time.

Fig. 9 also shows the RF-dc conversion efficiency of the rectifier with coupler versus output load ( $\left.\mathrm{R}_{\mathrm{LOAD}}\right)$ for a two-tone input power of $12.2 \mathrm{dBm}$ at $1.5 \mathrm{GHz}$.

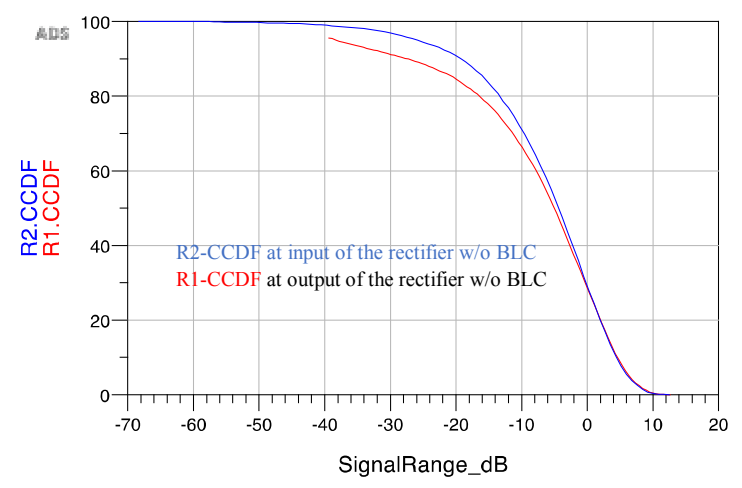

Fig. 3. Simulated CCDF of $5 \mathrm{MHz}$ FBMC waveforms of the rectifier without BLC at input power of $-10 \mathrm{dBm}$ 


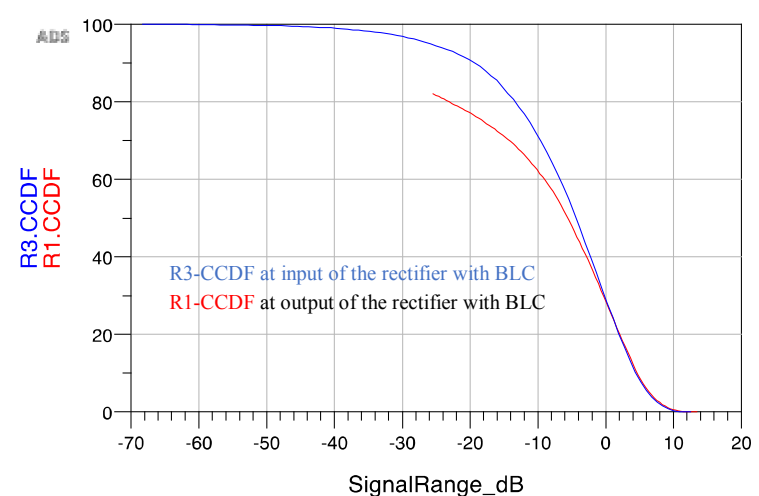

Fig. 4. Simulated CCDF of $5 \mathrm{MHz}$ FBMC waveforms of the rectifier with BLC at input power of $-10 \mathrm{dBm}$.

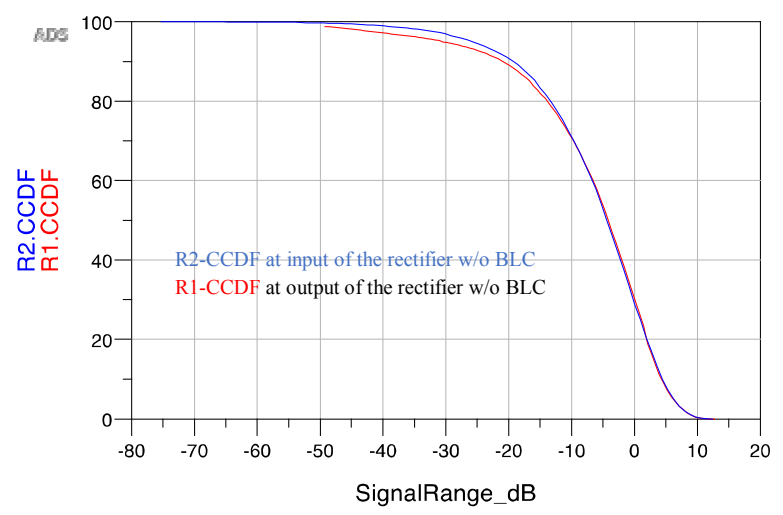

Fig. 5. Simulated CCDF of $5 \mathrm{MHz}$ FBMC waveforms of the rectifier without BLC at input power of $0 \mathrm{dBm}$

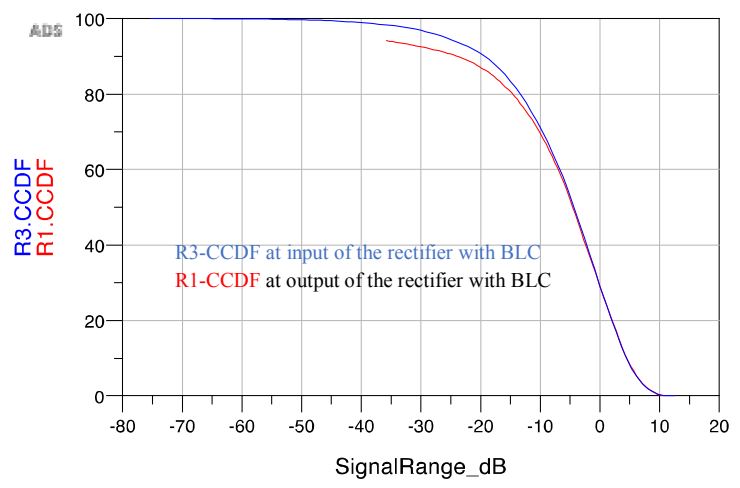

Fig. 6. Simulated CCDF of $5 \mathrm{MHz}$ FBMC waveforms of the rectifier with BLC at input power of $0 \mathrm{dBm}$

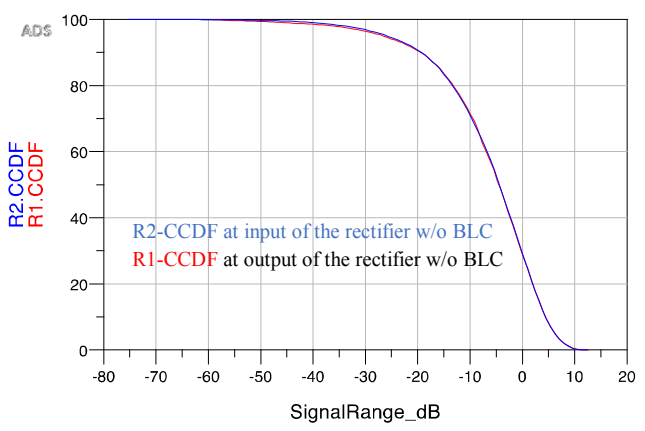

Fig. 7. Simulated CCDF of $5 \mathrm{MHz}$ FBMC waveforms of the rectifier without BLC at input power of $10 \mathrm{dBm}$.

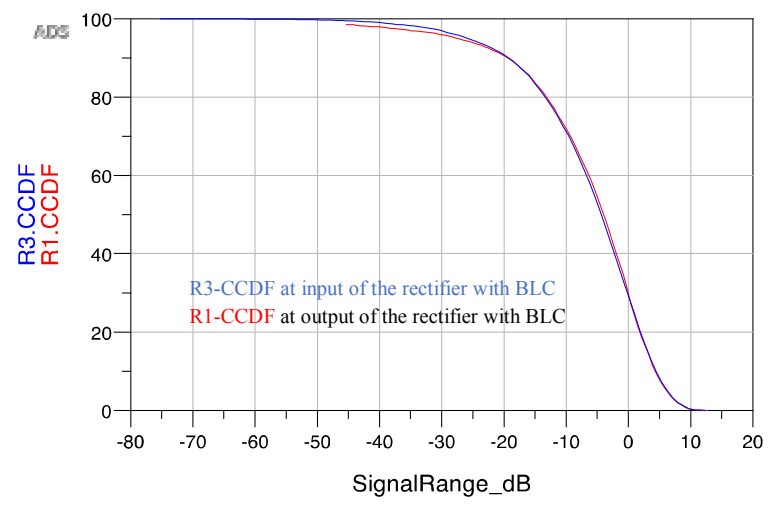

Fig. 8. Simulated CCDF of $5 \mathrm{MHz}$ FBMC waveforms of the rectifier with BLC at input power of $10 \mathrm{dBm}$

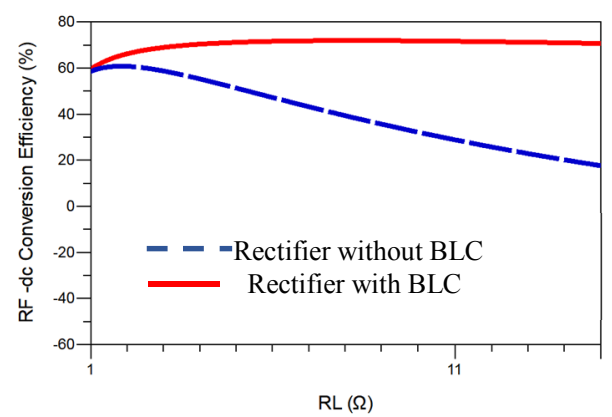

Fig. 9. Simulated efficiencies of the rectifiers with and w/o BLC versus output load $\left(\mathrm{R}_{\mathrm{LOAD}}\right)$ in $\mathrm{k} \Omega$ with input power of $12.2 \mathrm{dBm}$ at $1.5 \mathrm{GHz}$

\section{CONCLUSION}

In this paper, the impact of $5 \mathrm{MHz}$ 5G-FBMC waveforms on energy harvesting rectifier performance has been investigated. The $5 \mathrm{MHz}$ FBMC signals have been used to observe the CCDF effects. The proposed rectifier configuration will be very effective for the next generation low power sensor networks, IoT (Internet of Things) and 5G applications. 


\section{ACKNOWLEDGMENT}

This work was supported by UK India Education Research Initiative University Grants Commission under grant IND/CONT/G/16-17/63.

\section{REFERENCES}

[1] F. Bolos, J. Blanco, A. Collado and A. Georgiadis, "RF Energy Harvesting From Multi-Tone and Digitally Modulated Signals," IEEE Microwave and Wireless Components Letters, vol. 64, no. 6, pp. 19181927, June 2016.

[2] B. Li, X. Shao, N. Shahshahan, N. Goldsman, T. Salter and G.M. Metze, "An antenna co-design dual band RF energy harvester," IEEE Trans. Circuits and Systems, vol. 60, no. 12, pp. 3256-3266, Dec. 2013.

[3] J. Guo, H. Zhang and X. Zhu, "Theoretical analysis of RF-DC conversion efficiency for class-F rectifiers," IEEE Trans. MTT., vol. 62, no. 4, pp. 977-985, Apr. 2014.

[4] Y.-J. Ren and K. Chang, "5.8 GHz circularly polarized dual-diode rectenna and rectenna array for microwave power transmission," IEEE Trans. MTT., vol. 54, no. 4, pp. 1495-1502, June 2006.
[5] X.Y. Zhang, Z.-X. Du and Q. Xue, "High-Efficiency Broadband Rectifier with Wide Ranges of Input Power and Output Load based on Branch-Line Coupler," IEEE Trans. Circuits and Systems, vol. 64, no. 3, pp. 731-739, March 2017.

[6] K. Niotaki, A. Georgiadis, A. collado, and J.S. Vardakas, "Dual-band resistance compression networks for improved rectifier performance," IEEE Trans. MTT., vol. 62, no. 12, pp. 3512-3521, Dec. 2014.

[7] C. R. Valenta, M. M. Morys, and G. D. Durgin, "Theoretical energyconversion efficiency for energy-harvesting circuits under poweroptimized waveform excitation," IEEE Trans. MTT., vol. 63, no. 5, pp. 1758-1767, May 2015.

[8] E. Kofidis, "Preamble-Based Estimation of Highly Frequency Selective Channels in FBMC/OQAM Systems," in IEEE Transactions on Signal Processing, vol. 65, no. 7, pp. 1855-1868, April1, 12017.

[9] C. Kim, Y. H. Yun, K. Kim and J. Y. Seol, "Introduction to QAM-FBMC: From Waveform Optimization to System Design," in IEEE Communications Magazine, vol. 54, no. 11, pp. 66-73, November 2016. 